\title{
Determinants of Integration Approach in the Agrarian Sphere Development in Contexts of Transformation
}

\author{
Anatoly A. Smirnov ${ }^{1} \&$ Irina V. Stukova ${ }^{2}$ \\ ${ }^{1}$ Mari State University, Yoshkar-Ola, Russia \\ ${ }^{2}$ The Mari Institute for retraining of staff in agribusiness, Yoshkar-Ola, Russia \\ Correspondence: Anatoly Smirnov, Mary State Universiti, Room 435, Krasnoarmeyskaya St 71, Yoshkar-Ola, \\ Russia. Tel: 8-927-882-1202. E-mail: an2saa@bk.ru
}

\author{
Received: February 21, 2015 Accepted: March 15, 2015 Online Published: April 29, 2015 \\ doi:10.5539/res.v7n8p8 \\ URL: http://dx.doi.org/10.5539/res.v7n8p8
}

\begin{abstract}
The article discusses theoretical aspects of integration approach to the study of the development of the agrarian sphere of economy. The article presents authors who have made significant scientific contributions to the theory of integration; identifies structural elements of the national agro-industrial complex; determines the value of scientific and technological progress in the development and integration of productive forces; identifies factors affecting the development of the agrarian sphere as a complex integrated system. The article notes that integration as a system possesses characteristics of self-organization, hierarchy, striving for equilibrium, and has the presence of a common goal. The article particularly characterizes the socio-economic factors of integration, influencing the agricultural sphere development and management. Particular emphasis is placed on the problem of integration of Russian agricultural industries in the WTO.
\end{abstract}

Keywords: agrarian sphere, integration, integration approach, system of national agriculture, social division of labor, conversion process, forms of agroindustrial integration, socio-economic factors of integration, the WTO management

\section{Introduction}

Current economic situation, changes in approaches to the integration processes development, increasing need to take into account the actual socio-economic conditions, and transformation phenomena in the agricultural sector determine further study of the integration problem in the agrarian sphere.

At present the system of scientific and information support of the agricultural sector, and the formation of integrated interactions in its various fields are not fully developed. Adequate to market relations, scientific basis of integration forms and mechanism of their realization, and entry into the world economy contribute to elimination of barriers in the agrarian sphere development, joint production and commercial activity, food security, affecting the fate of 6.7 million people employed in agriculture, 1.5 million people working in food industry and almost 40 million people living in rural areas (Polyubina, 2012).

At various times, integration problems have been considered in the fundamental studies of domestic, Russian and foreign scientists such as M. I. Tugan-Baranovsky, A. V. Chayanov, N. G. Chernyshevsky, N. D. Kondratyev, A. N. Antsyferov, Ronald Coase, O. Williamson, John R. Hilferding Galbraith, H. Demsetz, R. I. Kapelyushnikov, D. North, A .G. Bespahotny, I. N. Buzdalov, L. I. Abalkin, A. I. Dobrynin, I. G. Ushachev, V. J. Uzun and many others.

\section{Results and Discussions}

Analysis of works of Russian scientists and economists Gataulin (2005), Ushachev (2011), Buzdalov (2011), Uzun and many other shows that the system of national agro-industrial complex includes a number of structural elements:

- Agriculture, where, as a part of basic crop production and animal industry, various kinds of agricultural raw materials (cereals, industrial crops, many kinds of animal products), final food products for fresh consumption (vegetables, fruits, berries, eggs, milk, etc.), as well as feed for livestock business are produced;

- Reclamation industry (in the system of food, light, flour-and-cereals and feed mill industries) whose companies 
produce food products including beverages, tobacco, leather, textiles and fibers;

- Food market, in the system of wholesale and retail trade, catering, adjusted for adequate foreign economic and interregional trade, the purpose of which is realization of various types of final agro-industrial products to consumers, including households;

- Resources providing infrastructure, as a system of industries and companies that produce and supply agriculture, forestry, fishery, reclamation industry and trade with various commodities: machinery, fertilizers and pesticides, feed, fuel and lubrication materials, electricity, purchased seeds, breeding animals, poultry and young fat stock, etc .;

- Information-technological service infrastructure, as a system of sub-sectors and enterprises engaged in purchase of raw materials and food, car rental and contractual works, repairs and basic funds maintenance, financial, transport, marketing, logistics and product storage services, etc.;

- Specific subsystem of the agro-industrial complex is a rural consumer cooperation, which in fact has all the structural elements of the agro-industrial complex, including agriculture, purchase of raw materials, agro-processing, trade, catering, as well as infrastructure.

Agricultural organizations, households and farming enterprises operate in agriculture. A variety of organizations and small businesses are characteristic of consumer cooperation, reclamation industry, trade and catering.

In the course of interaction, on basis of developing cooperation, integration, and in some cases on organizational basis (as a rule, within rural municipalities) we observe formation and functioning of product subcomplexes engaged in production, processing and realization of final product by sector on a particular type of agricultural activity.

In economic theory, the concept of "integration" is used to refer to a process of creating new economic groupings on basis of existing ones (Pilichev, 1977) as a result, amount, frequency and intensity of interaction increase, the system acquires more integrity and stability. Integration can also be defined as a process of establishing optimal relations which is based on activity of subjects satisfying needs.

Agro-industries, extremely different from each other in their organizational and technological structures, have a general property allowing them to become integrated - it is an objective need to get the most benefits of the production and promotion of agricultural products at the lowest cost. Each industry can function only with the availability of stable economic connections with related industries providing production and maintenance services. These connections have an integration character and a decisive impact on the process of reproduction in agriculture. The existence of stable connections between agriculture, industry and trade, as the main areas of the agro-industrial complex, is an objective condition of its effectiveness increase.

The development of the social division of labor naturally led to the formation of integration in the agrarian sphere which is understood as: the process of development of tight and sustainable interconnections based on an agreed economic policy; mutual adaptation and integration of economies; merger of economic subjects, deepening of their cooperation, development of connections between them; state of connectivity of differentiable systems and functions into a single unit, as well as a process leading to this state; the highest degree of division of labor.

For example, agro-industrial integration can be viewed as a result of production relations development on the subject of production and realization of agricultural raw materials and their derivatives to consumers on basis of interindustrial connections emerging in this process (Antciferova, 2011). 


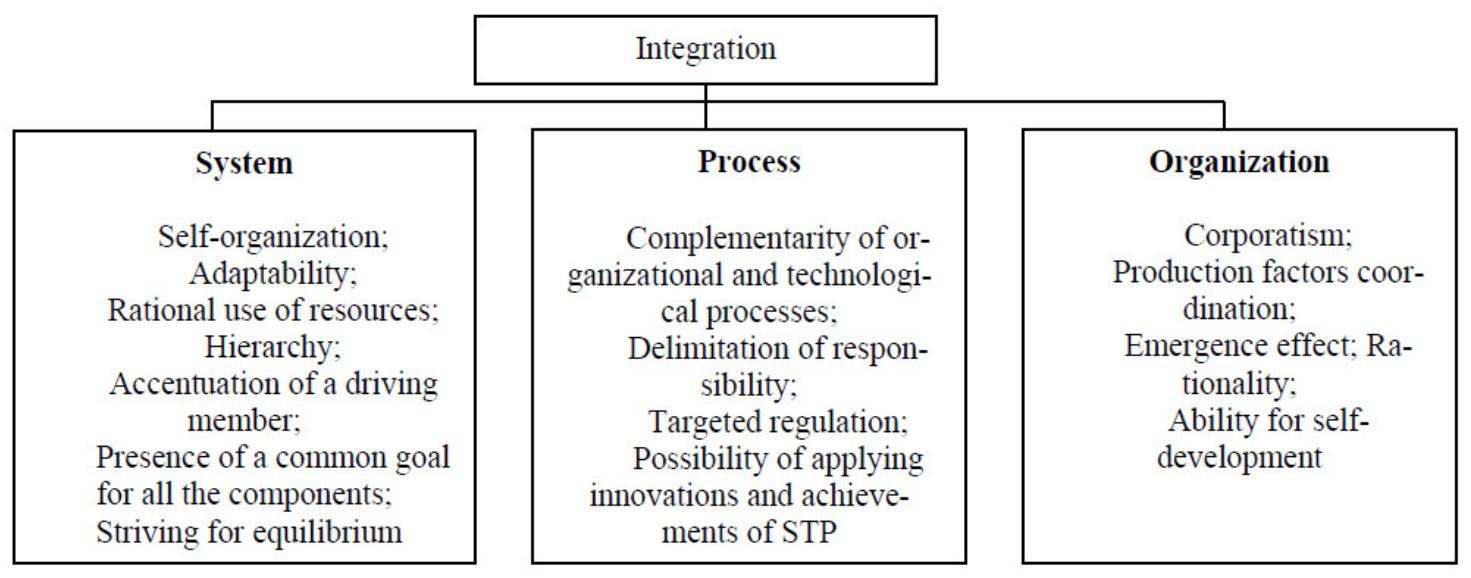

Figure 1. Structural characterization of essence of the "integration" concept

But taking into consideration a specific character of the agrarian sphere, one can note that integration as a system possesses characteristics of self-organization, hierarchy, striving for equilibrium, and has the presence of a common goal. The simplest element of integration as a system is connections between subjects that are initiators of this phenomenon. In addition, processes of production, distribution, exchange and consumption of material goods are fundamental processes of integration and are not performed without human participation. Equally, relationships between subjects are deprived of any content if they are not connected to the real side of the economy. Therefore, the basic elements of integration as a system can be subjects of integration, integration connections and processes.

Integration as a process is built on complementarity of organizational and technological processes, favourable conditions for implementation of scientific and technological achievements, targeted regulation, and from the point of view of its organization properties, integration possesses emergence, coordination of production factors, rationality and ability for self-development.

The agrarian sphere in socio-economic society development (including regional development) is positioned as a local subsystem able to develop on basis of interaction of economic entities operating simultaneously under general and individual laws (Frolova, 2012). Vertical interaction between the socio-economic and the agrarian spheres is represented by a number of local systems in the course of controlling the operation of the economic system. Service nature of higher order system influence is based on the feedback providing dynamic impact between local systems, and currently has an unfinished form, but in the future it will contain elements of a new paradigm of system management. Peculiarity of local system management is expressed in its properties and determined by implementation of various functions.

Gaps and destructions in the control system are conditioned by lack of fundamental standards in the interaction of organizations, that is, even availability of appropriate resources generates contradictions, conflicts and various transformations. The example of aforementioned is an ill-conceived strategy of entering the market of agricultural organizations based mainly on price liberalization, privatization and corporatization which led to the breaking of economic connections between industries and spheres of the agro-industrial complex, and, as a consequence, to the aggravation of contradictions in the agrarian sphere (Frolova, 2012).

Thus, we can say that the agrarian sphere is an integrable local system of social economy producing products based on reproduction of territorial community, environment and material resources belonging to the agro-industrial complex. Therefore, the mechanism of formation of organizational forms of interaction in the local systems ensuring effective management is based on the involvement of cooperation and integration processes generating, by virtue of their nature, new special forms and by that providing problem solving in new economic conditions. 


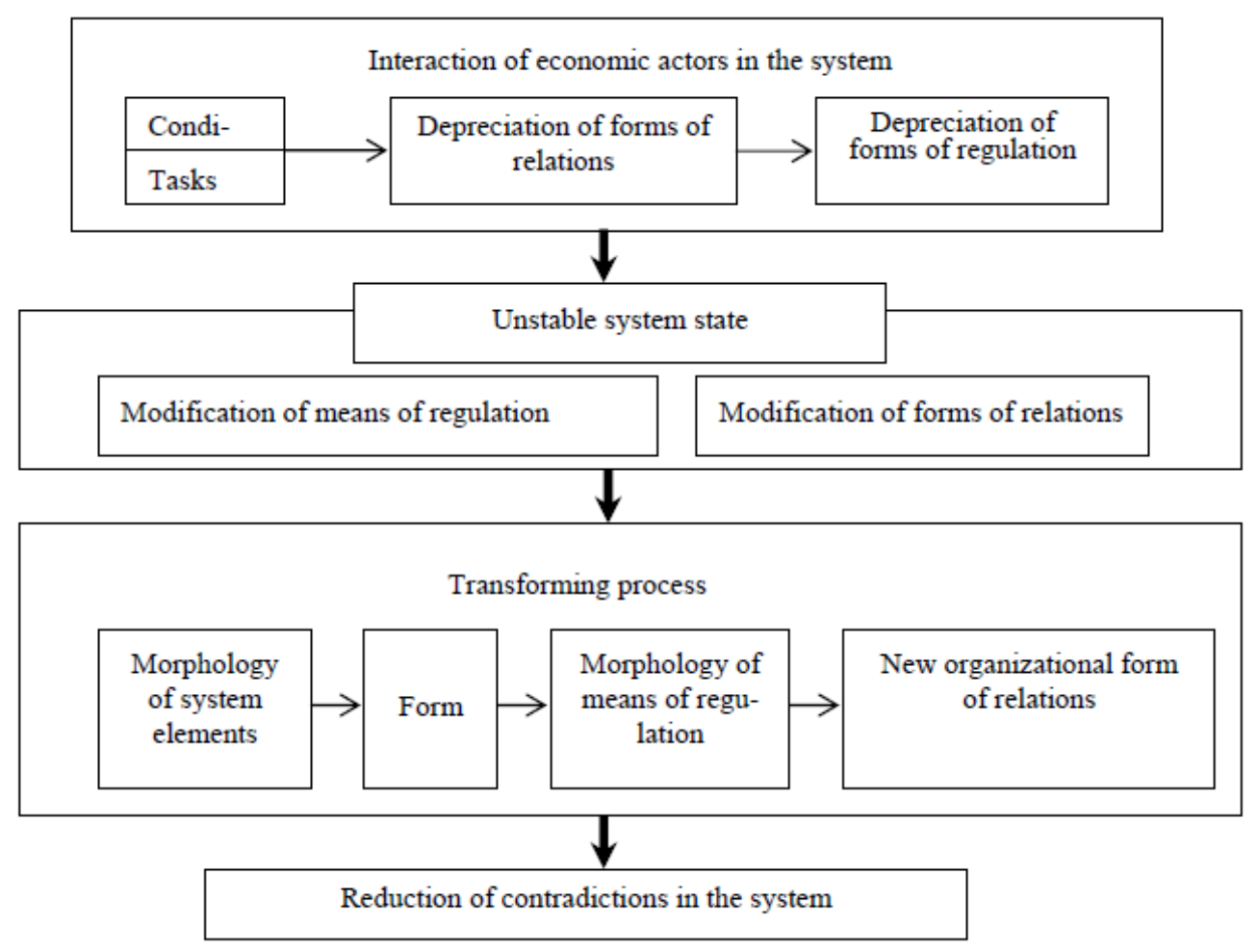

Figure 2. Interaction of economic actors in the system

Talking about the integrated approach in the agrarian sphere, it should be noted that in order to improve functioning of the agro-industrial complexes at all levels of production and develop their long-term planning, scientifically based classification of agro-industrial associations, and establishment of their rational structure are of particular importance. Academic economists [Batrasov V. I., Brazhnik M. D., Gontmaher E. Sh., Ivanov P. F., Kolesov N. D., Makeyenko M. M., Negru-Vodje A. S. and others) grouped differently agro-industrial complexes started at different levels of the national economy as a result of integration of agricultural and industrial production, but the point is to integrate production of agricultural raw materials with their storage, processing to finished product and to ensure its realization to consumers.

Objective basis for integration in the agro-industrial complex is a high level of productive forces, development of social division of labor, extension of connections between agriculture and other economic spheres. Scientific and technical progress acceleration amends traditionally formed functions: part of operations and processes develops into the industrial sector and is separated from agriculture; connections with industries involved in bringing products to a consumer are developed. The overall end result is increasingly dependent on balanced development of all the interconnected elements and their coordinated work. As a result, the process of integration becomes an objective necessity for development of productive forces, particularly when the role and importance of symbiotic relationship between individual elements of social production increase.

According to the theoretical regulations about synthesis of industry and agriculture, integration ,as a specific form of public division of labor, generates the new labor productivity (PAP), which can belong only to the cumulative worker of a certain type (agro-industrial) and differs from the simple addition of labor productivity of some separate branch productions: industrial $(\mathrm{P})$ and agricultural $(\mathrm{S})$. It can be also expressed by this formula: $\mathrm{PAP}>\mathrm{S}(\mathrm{P}+\mathrm{S})$.

Three options of consequences and its efficiency are possible on the basis of such approach.

Firstly, if on the basis of the rational placement, accurate work and reduction of losses at all stages of a production cycle of the overworking enterprises and farms of a raw zone, we see increase of efficiency of agro-industrial production, labor productivity of the cumulative worker of the integrated formation will be higher than a simple sum of labor productivity of independent branch productions, that is: $\mathrm{PAP}>\mathrm{S}(\mathrm{P}+\mathrm{S})$;

Secondly, if the productive and economic connections aren't rational in the integrated system, moreover if they 
can't manage good interaction between the partners for the integrated productions and increase of their economic interests, labor productivity of the cumulative worker of the integrated formation can be equal to the sum of labor productivity of the independent branch productions, that is: $\mathrm{PAP}=\mathrm{S}(\mathrm{P}+\mathrm{S})$;

Thirdly, when integration connections between the agricultural and overworking enterprises are developed poorly, or in general are absent, disproportions between capacities and raw material resources can take place, and the actual economic relations don't promote expansion of integration cooperation, labor productivity is less than productivity of the integrated work of branch productions, or $\mathrm{PAP}<\mathrm{S}(\mathrm{P}+\mathrm{S})$.It proves that the integrated system needs to find more effective organizational forms. In this way, the concrete forms of agro-industrial integration have to provide higher efficiency of work and production efficiency of the final products.

In this case, the formation of the integrated structures in agriculture is directed on the solution of the following tasks:

- To improve the productive and economic relations in the process of production, processing, storage and realization of agricultural products and raw materials;

- To increase competitiveness of local agricultural producers;

- To create an effective system of industrial, social and economic services for the members of the integrated structures;

- To increase efficiency of agricultural production and to provide increase of the level of material well-being of workers of agriculture and the villagers in general.

Integration into agrarian and industrial complex is urged to solve some social problems, leading to the problems causing the quantitative and high-quality shifts which can provide gradual deleting of sides between the city and the village.

Also one of the main social and economic purposes of the agricultural integration and cooperation is a creation of organizational and legal system of the protection of interests of agricultural producers by the creation of self-governed forms of managing.

The agrarian and industrial complex and agriculture are the integrated system, that's why some factors have an influence on its development:

- Social, acting in the sphere of public consciousness and psychology of the people. The social nature of production is one of considerable results of evolution of the person. Therefore, integration is the natural continuation of the evolution of public and industrial relations. The ability and desire to unite people are considered during the developing and realization of economic strategy of an economic entity. In particular, such element of strategy as vision is focused on subconscious and conscious aspiration of the people for the joint actions. It serves as the means of motivation; it unites the activity of the personnel. The individual initiative also takes a special part in the development of integration, first of all, the initiative of businessmen and experts. The aspiration to influence, recognition and self-affirmation is so high at this category of people that integration processes represent an obligatory attribute of the modern economy at the micro level);

- Economic (can be formed in the sphere of economic interests and ways of their satisfaction (increase in the income, property, free time). Achievement of these purposes is interfered by the increasing competition and limitation of resources. Integration allows eliminating the specified obstacles. In this case, there is interconditionality between economic interest and integration. Each of the phenomena acts as a factor and as a response at the same time.

Economic feasibility of integration consists in elimination of negative consequences of public division of labor, such as: increase of transactional expenses (mainly — costs of search of the partners in transaction and economic losses from non-compliance with obligations by them); unevenness (seasonality) in using of resources and receipt of revenue; considerable economic dependence of the specialized enterprises on demand for their production.

Also we can mark out next economic factors of integration:

- The aspiration to strengthen the influence on the price level (realized production and acquired resources);

- The necessity in the expansion of opportunities to work, proceeding from strategic objectives and prospects;

- The advantages of diversification. In this case diversification by joining up different types of activity and the diversified enterprises, functioning in various natural and economic conditions, allows to reduce the risks which can take place at highly specialized activity); 
- Organizational and legal factors (are concluded in the opportunities provided by the legislation (various organizational and legal forms of the enterprises);

- Organizational and technical factors (are defined by advantages - technological (are formed in the sphere of management of production and marketing activity. The necessity in integration arises here because next things are possible on its basis:

- To provide organizational unity of a production cycle; to carry out a complex of technological operations, proceeding from system expediency;

- To prevent losses of raw materials and finished goods;

- To use the modern administrative technologies focused on satisfaction of needs of end-users).

In the agrarian sphere the integration processes take place in conditions of multi structure economy and they are under the influence of such powerful economic factors as a private property and private economic interest and by means of:

- The merger of legal entities;

- Joining of legal entities to the existing organizations;

- Associations of property deposits of individuals at the creation of the commercial organizations;

- Expansions of number of participants of the commercial organizations (due to issues of shares and introductory property deposits);

- Distribution of influence of one organization on another by acquisition of actions of the last one.

Now we can see integration of branches of agrarian and industrial complex of Russia into the world market - the accession to the World Trade Organization (WTO). Emergence of steady demand at essential reduction of import stimulates development of the market relations, making impact on the branch. Steady demand is important for future agriculture and all Russian economy. But there is a set of opposite opinions about it. World experience testifies that the greatest contribution to ensuring national and international food security is brought by the countries which are not only producers, but are also large exporters of the food and the agricultural products. Strengthening of deliveries of domestic goods to a foreign market in combination with optimization of import conducts to creation of other situation. In this case Russia will start making the contribution to strengthening of world food stabilization.

According to the Russian and foreign scientists and experts, starting conditions for integration of Russia in global economy are extremely adverse. Firstly, the developed structure of foreign economic relations doesn't create a basis for long-term economic cooperation. The volume of the western investments in the Russian economy is rather small. Secondly, the raw orientation prevails in the structure of Russian export, and the goods and services connected with satisfaction a consumer demand prevail in the import. But, despite it, the country has a great possibility of expansion of export of foodstuff, however Russian enterprises will appear in more rigid competitive circumstances, the introduction of the standard quality standards in the world will become a necessity for many producers.

And, nevertheless, by the estimates of the World bank, WTO membership can increase GDP level 3.3\% next years. Now $2 \%$ of world trade fall to the share of Russia. According to Rosstat, $15.9 \%$ - the 3rd place in import, which is occupied by the food (Kara-Murza, 2004). Thus, the question of deeper integration of Russia into the international division of labor in the sphere of agrarian and industrial complex is rather important for the import countries of the food. The developed countries delivering the food on a foreign market give considerable support to the exporters. Obviously, Russia also needs to create a system of stimulation of export, including rendering information, marketing and advisory support to exporters, harmonization of internal and international standards, development of transport infrastructure, unification of tariffs for transportations of production.

In the next years Russia will be able to declare itself as a perspective exporter of separate types of food. Russian producers are able to expand deliveries to a foreign market of meat and fish products, confectionery products, drinks, grain, sunflower oil, milk canned food and yogurts, ice cream, juice, etc., and in the long term-environmentally clear production.

Realization of an export potential of agrarian and industrial complex will allow Russia to strengthen national food security and to increase the value in ensuring world food stability. However, in the next years the role of Russia in world food economy will depend on efficiency of the state support of national producers, adoption of the drafts of federal laws offered by the Ministry of Agriculture of the Russian Federation on development of 
agriculture, regulation of the grain market, etc. (Vintovkin, 2004).

\section{Conclusions}

Thus, on the basis of the problems of development of the integration relations in the agrarian sphere, application of integration approach take an important place in the modern economic theory, promotion of the scientific analysis to formation of complete system of theoretical views of essence of the agrarian relations and policy in general, and also more specific questions of the directions of development of agriculture following from this system are impossible without comparative comparison of various concepts. The analysis of these concepts allows to allocate from them positive aspects and to find out obviously unacceptable concepts, so we get chance of development of new models in agrarian and industrial complex;

- Integration into agrarian and industrial complex and agriculture can be performed as a result and possibility of the coordinated regulation of difficult, complex social and economic activity and that's why it has administrative and organizational character in attitude to process of fabrication and reproduction of production. Thus various processes of functioning of subsystems of the agrarian sphere don't merge with each other in one certain universal thing, but they keep the main initial character and unite in organizational economically processes under the common management. There is an integration of the differentiated subsystems;

- It is obvious now that the functions of the agrarian and industrial complexes organizations and agriculture are much broader, because they can be caused by diversification that assumes existence of the qualified personnel owning special knowledge allowing to introduce some new innovations, to support effective functioning of system and to realize the available potential in development of agro-industrial complex and agriculture;

- Possessing the unique resource potential of development of national agriculture, Russia becomes a platform of its further integration into the world economic sphere, a repositioning in structure of the international division of labor, so in the long term it will create additional instruments of overcoming of social and economic problems of intra economic differentiation, increase of competitiveness of regions, also it will raise sovereignty of the country in the globalized economy and will give alternative opportunities of its economic progress.

\section{References}

Antsiferova, O. U. (2011). The development of cooperation and integration processes in the agrarian sphere of economy: Theory, methodology, practice (Master's thesis, Mitch-rinsk-science city Russia).

Buzdalov, I. N. (2011). How to provide a priority of rural development. Agrarian and industrial complex: Economy, management, 7, 13-23.

Frolova, O. Ya. (2012). Management of system changes in creation of a paradigm of social and economic development of the agrarian sphere. Retrieved from http://www. Kgau.ru://img/konferenc/2012/e4.doc

Gataulin, A. M. (2005). Introduction to the system analysis. Moscow. MSHA.

Pilichev, N. A. (1977). Management in agricultural production associations. Leningrad, Pushkin: LSHI.

Polyubina, I. B. (2012). The part of the agrarian relations in the development of economic system of society. Retrieved from http://elib.altstu.ru/elib/books/Files/pa1999_3/pages/27/pap_27.html

Sukharev, O. S. (2012). Evolution of economic systems: structural changes, problems of technological development and efficiency (p. 120). Novocherkassk: "NOC".

Torgachev, D. N. (2011). Formation of a new theoretical paradigm of social and economic development. Regional economy: Theory and practice, 158(2), 33.

Ushachev, I. G. (2011). Integration-The most important factor of development of an agro-industrial complex of the CIS countries. Agrarian and industrial complex: Economy, management, 7, 3-12.

Uzun, V. Ya. (2008). Agrobusiness feathered. Retrieved from http://www. rg .ru/2008/12/30/selo-reyting.html

Vintovkin, P. S., \& Yudin, V. E. (2004). Prospects of increase in production and export of the Russian agrofood production. Informational bulletin of the Ministry of Agriculture and food of the Russian Federation, 1.

\section{Copyrights}

Copyright for this article is retained by the author(s), with first publication rights granted to the journal.

This is an open-access article distributed under the terms and conditions of the Creative Commons Attribution license (http://creativecommons.org/licenses/by/3.0/). 